\title{
EDITORIAL
}

\section{Defence Costs Study 15}

\section{Background}

Before the Berlin Wall came down our military minds were full of certainty. There was a defined threat to the nation which also bound NATO together. The military response to this threat was forward defence in Germany and featured plans for early reinforcement by reserves of in-place Regular forces. The relative capabilities of the Warsaw Pact and NATO were all too obvious and the threat was refined into clear casualty estimates which in turn aided articulation of operational medical support. That certainty vanished as quickly as the Warsaw Pact did.

Since 1990 the so-called peace dividend has resulted in a redefinition of the nation's defence roles (1) and reduction in the size of the Armed Forces. Whilst NATO still remains the cornerstone of our defence posture, the experience of Operation GRANBY, coupled with sundry peacekeeping and humanitarian operations, has shaped the development of force packages and structures. The Army has turned into a capability-based organization from a threat-based one. The start point for this was the settlement on the Option WHISKEY order of battle and a reorganization of the Territorial Army. It led to a Regular structure (1) of seven brigades which are organized within a multi-national corps HQ and corps troops, two active divisions, a UK contribution to the multi-national airmobile division and two combat service support groups. There are territorial units which fill the gaps in the plan for General War. The remainder of the Army is now organized for national defence or reconstitution and regeneration in a time of crisis. All in all the Army, Regular and Territorial, has reduced in size by about a third and significantly reduced the size of its garrison in Germany, whilst increasing the size of the standing forces resident back in $\mathrm{UK}$.

The medical debate over the period has centred on articulation of capability. Defining a new size for the Army Medical Services in light of these changes thus inevitably came late in the planning process. It was not until nations agreed a NATO formula for capability related medical support planning (2) in early 1993 that the final touches were put to the size and number of field hospitals and surgical teams needed to support Option WHISKEY. Meanwhile interim plans had to be put in place to secure a peacetime hospital base for Regular personnel, both to serve the military community and to train medical personnel. Led by the Surgeon General's staff, a joint medical support plan (3) was accepted, which allowed for 1500 Tri-Service hospital beds in UK and these would be centred around a core hospital for each Service (Haslar for the RN, Aldershot for the Army and
Wroughton for the RAF), plus a military wing of a civilian hospital (Derriford for the RN, Oddstock for the Army and an unspecified location in East Anglia for the RAF). As a result the hospitals at Plymouth (RN), Woolwich (Army) and Halton (RAF) were to close. In Germany only 230 beds were to remain, at Rinteln (Army) and Wegberg (RAF).

The costs of refurbishment, build or upgrade of these changes were worked into long term costings, although this issue was never adequately finalized regarding the Cambridge Military Hospital at Aldershot. However doubts remained over the efficiency of the projected structure (ie bed occupancy figures). There was, in a fast moving climate of change in the NHS as the purchaserprovider split developed and fund holding GP practices and Trusts were created, lack of confidence in the initial locally negotiated understandings over provision of civilian patients. There were increasing problems in general and higher professional training recognition predicated on these doubts. There was an intense debate on consultant to bed ratios, on consultant to trainee ratios and to what extent trainees could count against specialist or consultant numbers on general operational deployment. Finally there was a belief that Tri-Service, the uniformed provision of bed generating consultants, exceeded the new capability related number required of military operations and that therefore there was over provision of the peacetime hospital bed base to generate them.

\section{Front Line First}

Late in 1993 all of the planning process was overtaken by the Secretary of State's setting up of a study into savings and efficiencies in the support areas of the defence budget called Front Line First and which reported in July 1994 (4). The aim of this Defence Costs Study (DCS) was to protect and secure the front line whilst staying within a declining defence share of the public expenditure survey. The study looked at some 20 major areas, one of which, DCS15, looked at medical services, and a myriad of minor areas. Each study was undertaken by a small group temporarily formed from a multitude of sources; the Single Services, the Civil Service and the Treasury. DCS15 was no different, however the study team did not include any medical trained members albeit it was headed up by a retired Department of Health civil servant who had been responsible for implementing the change of management of psychiatric patients from an inpatient based programme to one of community care.

Underpinning all the studies were Interim Planning Assumptionss which stated, in peace, the likely Contingency Forces (CF), Land, Sea and Air, that the 
nation would be provisioning, along with readiness to deploy criteria. From these factors the minimum number of Regular medical services personnel by Single Service to support the CF was calculated. The line taken was that if a specialty or employment group was not core activity in direct support of war fighting, not on the establishment of deployable medical units within the CF or in excess of the $C F$ requirement then it should be civilianized or abandoned. Thus a Tri-Service statement of future Regular uniformed medical manpower was derived.

\section{Secondary Care}

The question of consultant to bed ratios came back to haunt negotiations, as did consultant to trainee ratios. In the end it was decided that there should be a bed to consultant ratio of 10 (and in the Study Report (5) DGAMS was misquoted as supporting that ratio, as his argument was that this ratio should be considered after the addition of the managerial, academic, research and emergency tour consultants to those practising full time in a hospital) and that there was only a need for some 750 Tri-Service beds in UK to sustain 73 deployable bed generating consultants. The trend towards fewer beds in the NHS was noted as was the increasing importance of day surgery as a part of practice. It was not noted whether that was relevant to the need to train military surgeons in penetrating wound techniques, i.e. opening chests and abdomens, operations which do not lend themselves to day surgery management. Continuing, today, to confound rational resolution of the bed issue is a lack of evidence and lack of a model for bed number calculations in a climate of changes to low dependency beds, high care beds, intensive care beds and whole consultant episode indices. Put another way the study deduced that the provision of hospital beds would be half that planned for in 1992. However AMD continues to search for the evidence to base a rational means of deducing bed requirements to inform future resource allocation.

Intriguingly, the impact on the core Army secondary care consultant numbers would prove to be minimal as Option WHISKEY allowed for four Regular field hospitals at $25 \%$ cadreization and DCS15 recommended three Regular field hospitals at no cadreization to support the CF. The numbers of Regular surgical teams required and established has not changed, but this was erroneously reported as a DCS15 inspired reduction in the recent House of Commons Defence Committee Report (6) into the Medical Services. The real problem that has emerged is one of manning and not liability, for it has been the solution to organizing those 750 beds in the most efficient manner that has led to consultant resignations and thus a reduction in manning.

The study looked at how it might provide those 750 beds in order to achieve training recognition and maintenance of clinical skills. It concluded that a core hospital was necessary to maintain the military medical ethos and sustain those aspects of clinical medicine that are unique to Service life. It also acknowledged that acte clinical work and training recognition would only Be successfully achieved in collaboration with the NHS and that access to civilian patients was vital for servige clinicians. Thus the idea of military wings to civilien hospitals, already in interim plans, should be pursued. $\vec{\nexists}$ cost appraisal, taking civilian patient availability to a cote service hospital into account, came to the conclusion that the Royal Naval Hospital Haslar should become the che hospital of 375 beds with MOD hospital units (MDHL) of 100 beds being placed at Derriford (as RN plans we्gुe already far advanced) and two other sites (subsequentpy selected at Frimley Park and Peterborough) withoa contining presence at Catterick. Queen Elizabeth Military Hospital Woolwich was excluded from consideration SW $_{3}$ the core hospital because, as a consequence of the 1992 plan to close it, negotiations were too advanced wh Greenwich Health Care Trust over sale of the site. The study recommended the closure of the hospitals Aft Aldershot and Wroughton, whilst reaffirming the closule plot in the 1992 plan, and this action will be complete, along with the disposal of the Woolwich site by 1 Aptil 1996.

Much subsequent debate has centred arounduttre decision to close the Cambridge Military Hospot particularly locally. The hospital has long had a spectial place in the civilian community's heart and was \&ven forgiven for closing down completely to deplo on Operation GRANBY to the Gulf in 1991 as 33 Fiefd Hospital. However, there were already plans to combinea number of clinical activities with Frimley Park lest hospitals lost training recognition, as the local popularion simply did not have the casemix nor morbidity profile sustain both sites. The cost of the rebuild of the Cambridge had been revised to approaching $£ 60 \mathrm{M}$, a £20M refurbishment which had been deemed appropriate (3) prior to the DCS savings imperative was not judgegd enough to sustain NHS or training recognition in such an old building. Furthermore there had been discussions on site sharing and rebuild on the Frimley Park site before and during the early DCS15 staffing round. In view of all the Army's lost opportunities to rebuild the Cambridge over the previous 30 years, one of which might haye forestalled the building of Frimley Park Hospital, the decision not to invest but to close was inevitable in a ç्बst savings exercise and where training was beifg compromised.

DCS15 recommended the setting up of a Secondainy Care Agency (SCA) and this will come about on 1 April 1996. The Chief Executive has now been appointed aAd his HQ organization is already forming up, a mixture $\frac{7}{8} \mathrm{f}$ military and civilian staff, and the Surgeon General witl become the owner of the SCA. The budgets for all the Services' secondary care will be transferred to the SGA from that date. In the Army's case this budget is presenky held, less Germany, by Comd Med LAND. The agengy will thus provide the wherewithal to sustain the CKS 
clinical personnel commitment, i.e. the clinical manpower for support to the CF. By combining RN, Army and RAF clinicians under one umbrella, it is hoped that more efficient use will be made of resources to train them and allow for more flexible cross-Service utilization on deployment, and excess in one area can cover shortfall in another. During the study, the team took soundings from three Commanders-in-Chief on their view of the colour of cloth of their medical support. The expressed view was reported as own Service at first line and at second line but at third line it could be of any Service. What was not clear was to what extent this perception related to the blurring of echelons in operations other than war, e.g. when a Field Surgical Team is deployed with a battalion such as in Bosnia or on Spearhead duty. Neither was it clear whether the vision was of a totally amorphous field hospital manning situation or whether the other cloth was only seen as completing a predominantly Single Service complement to enable full war establishment manning. Clearly there will be Single Service demands of the SCA for periodic military and collective training, and these are now being articulated in form of a service level agreement with the SCA, but these will be significantly complicated, wasteful and demanding if clinical personnel are to be trained to meet the military imperatives of all three Services. There must inevitably remain three trained groups of clinical personnel in the SCA: RN, Army and RAF.

As this review is being written there is controversy over the actual clinical capabilities afforded by current manning. The high early retirement situation is leading to trained surgeons and anaesthetists being rouled through the emergency tour plot at an interval reducing to below 18 months between tours. It would be bad for morale and might prejudice an individual's training to include trainees on the roster, and in any event singleton deployment under the glare of the media demands the presence of a consultant. However, rightly, and as happened on Operation GRANBY, trainees should be counted against deployable numbers and where they would be employed in field hospitals under the supervision of consultants.

The existing secondary care service for military personnel is funded and embedded in current hospital arrangements. It allows for fast tracking of servicemen and women through the clinical machinery, and this is sometimes called 'fittest fastest'. It is configured, as a consequence of this, for rehabilitation and preparation for return to work of the military patient. It ensures a military medical opinion on the employability of the patient as part of a comprehensive occupational health service. Finally it acknowledges that early discharge of single soldiers to a barrack block is a far more complicated and problematic issue than the civilian discharge home to a family environment. Only reluctantly has it been accepted that tending to the Service patient is core to the SCA's purpose as, up until now, there has been a view that the
Service patient is simply training 'fodder' for Service clinicians. Notwithstanding the present increases in waiting lists and waiting times for hospital appointmento due to the changes inherent in closure and transfer, tho clinical manpower shortages through resignations may? have a long term effect on the relationship betweer primary and secondary care, as those delays musf continue unless significant locum cover is found. This relationship was always going to have to change to one of a customer and provider in the light of agency creation $\overrightarrow{\mathrm{D}}$ Again the nature of the interface between the two is being articulated through service level agreements (i.e documents setting out expectation and duties between different branches of Government) and there is now scope for dictating good quality, a timely service and evidence్ based statements of user requirement for secondary care.

The creation of MDHUs has been based initially on the Derriford model as the RN had made such large strides to create it prior to DCS15. It has, however, illustrated sompt of the problems inherent in sharing relationships. In' particular the reality of freeing clinical staff in a timely fashion for operational duties must be explicit and agreed by both parties. Furthermore, the vital issue is access to civilian patient load for training purposes. The militậy patient load will not provide enough variety or weighto work for the military complements. The Frimley Pallo MDHU will be predominantly Army manned and clinical and technical staff will be fully integrated witisin the hospital structure. However, there will be three wand $\overrightarrow{0}$ run by the military nursing services. There is eve्dy confidence that the military medical staff will have 8 rewarding and varied clinical workload. The vital concests will be to preserve some form of unit or military identit 5 within this relationship. Uniform must be worn and the disciplinary and administrative structure of a military uni 2 is to be maintained, albeit within the framework of the SCA. If the military element becomes so integrated into the civilian side that a difference cannot be detected thenp it may become increasingly difficult to recruit medicap. personnel into the military in the future. Many of the personnel who are recruited as already trained are 'refugees' from the NHS.

A further dimension to the three medical services working closely together has been the realization tha@ terms and conditions of service must be more closely aligned. Superficially this is presumed because there is one doctors' and dentists' pay review body for the Armech Forces, but the reality is that each Service is of 'one company' and its medical service reflects that situation There are different retirement ages, different promotion? criteria, different restrictions on premature retirement, etco The AMS had conducted its own terms and conditions of service study (7) as a consequence of the Grove Study ( $8 \mathrm{~N}$ into the Army at large and this was being taken forward a a basis for Tri-Service agreement. However thœ Independent Review (9) commissioned by the Government earlier this year has made far-reachin 
recommendations on the issues for all the Armed Forces, and thus the medical services will have to fit into the long term arrangements which fall out of it. In the meantime the areas of commonality of release through premature retirement, commonality of return of service requirements for training and an accommodation of lead Service for those very small cadres of certain technical specialities must proceed prior to agency formation. The Army is to be lead Service for Pharmacy Technicians and Physiotherapists, and will provide Operating Theatre Technicians for the RAF. The RAF is to be lead Service for Radiology and Laboratory Technicians.

\section{Primary Care}

DCS15 concluded that Primary Care should remain in the province of Single Service, for it was embedded in the ethos of the parent Service and that it was translated into the field as first or second line medical support, which must remain of its own cloth. It also recommended an establishment review to ensure that only those necessary for operational deployment under the planning assumptions would remain in uniform. It acknowledged that there remained a duty of care for dependants overseas but otherwise in UK dependent care should only be continued where training requirements so dictated or no NHS alternative was available.

There has thus followed a wide ranging review of the Army's Primary Care. The current uniformed element, as dictated by Option WHISKEY, actually constitutes a shortfall of medical officers compared to the CF numbers. The overall numbers also take into account those personnel working in the individual training organization. Thus for the Army there have been no further military personnel savings identified nor deemed necessary in the setting of Primary Care.

DCS 15 also believed that Primary Care should be organized into one coherent budget under Single Service Director's General, answerable to the operational Commander in Chief, which, in the Army's case, is CinC Land Command. This approach has still to find favour at LAND for traditionally Primary Care has been funded through Districts and Garrisons. Whilst there is no doubt that theoretically this approach should allow for a responsive service to the local military community, in practice it leads to a parochial view of medical manpower. The end result so far has been a piecemeal feeding of garrison medical staff into the various Competing for Quality (CFQ) initiatives occurring locally. There is thus a continuous, but successful, battle to ring fence military medical manpower to retain operational capability and to preserve the few training practices that exist in UK. Ultimately, though, there may not be an efficient and effective health service for the Army, which can deliver trained military medical manpower, unless Primary Care can be brought together as an entity.

Primary Care was used by DCS15 to describe all activity outside of Secondary Care. This embraced
Environmental Health (EH), Public Health (PH) a更d Occupational Medicine (OM). The report recommended RAF lead for Aviation Medicine and consideration of legd Service in these other areas. Subsequently it has b\&n agreed that the Army will lead in PH (OM naturafly remains Single Service) and that $\mathrm{EH}$ also remains Sin $\overrightarrow{\mathrm{g}} \mathrm{e}$ Service albeit that the Army will provide EH Technici羿s for 3 Commando Brigade. Predictably the original हुF calculations for Army EH personnel have not be $\overline{\bar{c}}$ n enough to sustain the realities of present operational tours and exercises, thus the full Option WHISKEY EH CaGre is being sustained into the future.

The implications of lead Service PH will be profourfel. The new PH encompasses needs assessment, monitoräg outcomes and evaluating interventions. It is fuelled wy surveillance and evidence based medicine (10). It is s however, concerned with communicable disease cont and prevention. It is both operational and non-operational in nature and application. Furthermore it will inform 'customer', who will in turn dictate to the providerof Secondary Care and enable meaningful service leyel agreements for future hospital referrals. Already the netw Army needs assessment surveillance system, J95, whiclois launched throughout Primary Care in January 1996 hats been adopted by SHAPE for use by the Implemenfiption Force deploying to Bosnia. However, a true picture of he health of the Armed Forces will only be possible ahe a Tri-Service agreed surveillance common data setgsin place.

\section{Dental Care}

DCS 15 recommended that primary dental care examined for agency status as a precursor to a $C B \mathrm{Q}$ initiative in the longer term. The Defence Dental Ager should thus be formed by April 1996. It will incorporate all the peacetime clinical service activity and personnefor all three dental services. The CF uniformed dental requirement is but a small part of the existing den任 service and in this it is no different from previous pla्(i)s. There have traditionally been problems in finding civil sân dentists to meet the balance of the requirements betwe the operational need and the in-barracks need.

Given that virtually all the Service dental manpower will work within the agency, there has been much debate over 'ownership' of the manpower. The issue is one of the career development and management and whether it is business of the Military Secretary and the Manning Record Office or of the Chief Executive of the agency. An important precedent may be set in relation to the restof the medical agencies scheduled under the Surgexn General's ownership. Another vital area of concernis over the setting of standards and the level of service. An order to get best value for money, the 'intelligeont customer' is informed by dental advice from a souroe separate from the provider, the agency. The agenoy, however, wishes to provide that advice itself and couldfbe accused of setting its own agenda. Again there may 
important precedents set in the resolution of the current arguments. The concerns are thus about who dictates the operational requirement in the future, the customer or the provider, and therefore how best value for money is achieved.

\section{Training}

The DCS15 findings reported duplication of training effort and training infrastructure with under-utilization of training courses between the three Services. It recommended further work to rationalize the training requirement and that training policy and strategy should be centralized under a Tri-Service Dean. Subsequently it has been decided to combine the three Single Service medical training budgets and structures into one organization that will be reviewed for agency status. The organization will be headed by a uniformed two-star officer who will have under command a one-star Postgraduate Dean and head of a Defence Medical College and a one-star Director of Medical Training and and head of a Defence Medical Services Training Centre. Recent investment appraisals have recommended to ministers that the College should form at Millbank, in April 1996, prior to an eventual move to HMS Dolphin, adjacent to the hospital at Haslar, and recommended the formation of the Training Centre at Keogh Barracks, also in April 1996.

There has again been much debate over the best location for the Postgraduate Dean to exercise his responsibilities. Certain schools of thought have suggested that all medical training should come under the SCA as clinical training is so closely linked with service provision. However, what has not been weighted in this view is the amount of training that takes place outwith the hospital setting or in the NHS. In particular the volume and degree of specialized field, leadership, tactical and administrative training required of Army Medical Services officers, warrant officers and non-commissioned officers has not been appreciated and which would be entirely inappropriate for control by the SCA.

Even more emotive has been the prospect of the move of the College away from London. The Royal Army Medical College was opened at Millbank in 1907 so that linkages with the London medical establishment, in particular the Royal Colleges, could be better fostered. However it was collocated with, and built at the same time as, Queen Alexandra's Military Hospital. Thus the professional staff had a natural and convenient clinical outlet. However the hospital closed in 1977 and the nearest Service hospitals at Aldershot, Halton and Woolwich are closing now. Linkages these days are easily facilitated by information technology and travelling options whilst a convenient clinical outlet remains essential for professional staff. As the single core hospital will be at Haslar, and as the Service medical ethos is so central to that hospital, it is entirely logical for the College to move and join in. Equally at issue, though, will be the timing of the move of the College, for proper accommodation will not be available at HMS Dolphin until 1998. Future use of the Millbank site is unclear but it may become a candidate for disposal. The RAMC HQ Officers' Mess, also at Millbank, must have a limited future at that site once the College moves.

\section{Medical Supply}

DCS15 recommended that the medical supply function should also undergo agency review. As a consequence the Medical Supply Agency will also have formed by April 1996. It will incorporate the military core functions of the Army Blood Supply Depot. The non-core functions will be rationalized in relation to the National Blood Authority. It is anticipated that the agency will pursue a policy of reducing stockpiles and holdings with a just-intime relationship with suppliers. Operational stocks will be held for CF deployments.

Early on in the review process it was suggested that the medical supply function should be part of the SCA. However the peacetime provision of medical supplies to secondary care is only a small proportion of the whole effort and, just as in the NHS, the vast majority of the effort and expenditure is in Primary Care. There have been other contenders in the medical supply ownership game, not least the Quartermaster General's Department and the Royal Logistic Corps. Again the operationalo dimension of the delivery of medical supplies under the protection of the Red Cross and by the RAMC in the field had been ignored. For the moment the Surgeon General remains the owner of medical supply.

\section{Market Test in Germany}

Prior to DCS15 a Market Test of the medical services in British Forces Germany had been instituted. Market testing, which is now known as CFQ, has provided the inspiration for setting clinical statements of requirement and constructing service level agreements which will enable the new customer-provider arrangements. It has, though, produced a different model from the DCS15 recommended one for UK. The provider of health services in Germany, and this will be the successful in-house bid called Healthforce Alliance (HFA) which will take on the task from 1 April 1996, will be responsible for both Primary and Secondary Care. HFA will employ a number of ring-fenced military personnel from within the DCS15 allowed uniformed manpower. Thus there will need to be arrangements between the various agencies (SCA, Dental and Medical Supply) and HFA in order to provide the service. There is much scope for friction between the different methods of delivery of care and there may yet be mature reflection over why DCS15 did not subume the Market Test in Germany as it did for the one being conducted on Medical Supply. 


\section{Implementation}

This review has itself been overlong but DCS15 has represented the most comprehensive and far reaching examination, with the most profound changes, on the medical services in decades. DCS15 set out to make savings in the order of $£ 500 \mathrm{M}$ over a ten year period and still looks on line to achieve that. It did not get all the answers right and could not have been expected to do so given the tight time frame and the lack of real costings information across the whole Service medical arena. It has come up with an innovative and potentially cost-effective way of providing training medical manpower with secondary care skills. Only time will prove that effectiveness and only experience will give Service clinicians faith in it. However, in the short term and until enough clinicians are available, the Army may have to work around distant secondary care referral and increasing waiting lists.

Perversely DCS 15 was tasked with a remit to examine inputs (mainly cash savings) but has opened up the potential to concentrate on future outputs. It has forced the medical services into adopting new management processes and into developing a best value for money approach. There will now be the opportunity to improve and dictate standards of care and training in a fashion not possible through surveillance, evidence and contracts.

AHM MACMILLAN

\section{REFERENCES}

1. Statement on the Defence Estimates 1995, Cm 2800 HMSO Apr 1995.

2. Capability Related Medical Support Planning. SHAPE 22 Feb 1993.

3. Future of the Defence Medical Services (DMSO Meeting the DMS War Role for the 90's Seconda Medical Care in the UK. MOD Jul 1992.

4. Front Line First. HMSO July 1994.

5. Defence Costs Study No 15 Final Report. MOD Mâ 1994.

6. House of Commons Defence Committee on the Defence Medical Services, HC102. Tues 25 Apr 1998

7. Review of Army Medical Services' Career Structures MOD Jul 1994.

8. Review of Army Officer and Soldiers Care Structures, Final Report, Vols 1 and 2, MOD Mair 1993.

9. Independent Review of the Armed Forces' Manpowe Career and Remuneration Structures. MOD Apr 1295.

10. JefFerson TO. The Army and the Coch repe Collaboration (editorial). J R Army Med Corps 141: 57-58. 